\title{
Irrational Behavior of Youth When Taking Financial Decisions
}

Submitted 08/01/19, 1st revision 26/02/19, 2nd rervision 28/04/19, accepted 29/05/19

\author{
Stepanova, D.I. ${ }^{1}$, Garnov, A.P. ${ }^{2}$, Brykin, A.V. ${ }^{3}$, Jancikova, E. ${ }^{4}$
}

\begin{abstract}
:
Purpose: The article contains research on internal factors of irrational behaviour initiated by the objective to reveal correlation between individual and personal, psychological peculiarities and irrational behavior in life situations.

Design/Methodology/Approach: The article is based on a hypothesis that there is a correlation between personal peculiarities and an irrational choice when students of economic HEIs make decisions of economic nature. Such life-purpose orientations as "Locus of control - Me" and "Locus of control - Life" are connected with irrational economic behavior.

Findings: The study allows enriching the subject field of behavioral economics from the point of view of the specificity of economic and psychological characteristics, attitudes towards an economic choice, and the identification of emotional and personal indicators of irrational behavior. It has been revealed that the psychological characteristics of a person (mental processes, orientation of an individual, life-purpose orientations) influence students' irrational economic behavior.

Practical Implications: The results of the study can be used by economic institutions (HEIs) in the selection of students for educational programs. The developed diagnostic game technique, the styles of irrational behavior described by the authors can be used in the practice of the educational process of economic HEIs or in assessing the propensity to make irrational economic decisions in other areas of human activity
\end{abstract}

Originality/Value: The main contribution of this study is the clarification of factors of finacial behavior of youth.

Keywords: Rationality, rational economic behavior \& thinking, economic irrationality.

JEL codes: D14, D81, D91.

Paper Type: Research article in Special Issue dedicated to Russian Economy.

Section 8: Business and Economic Issues.

${ }^{1}$ PhD, Associate Professor, Department of Finance and Prices, Plekhanov Russian

University of Economics, Moscow, s_diana@mail.ru

${ }^{2}$ PhD, Professor, Department of Economy of Industry, Plekhanov Russian University of

Economics, Moscow.

${ }^{3} \mathrm{PhD}$, Professor of Financial University under the Government of the Russian Federation, Deputy Director of Roselectronics holding, Moscow.

${ }^{4}$ PhD, Associate Professor, Department of International Economic Relations and Economic

Diplomacy, University of Economics in Bratislava. 


\section{Introduction}

According to Russian legislation, adolescents from the age of 14 can act as active subjects of economic relations and be registered as private entrepreneurs. Almost all high school students can realize the main economic functions of a producer, a buyer, a consumer, a seller, an entrepreneur and a taxpayer. However, the psychological models of rational economic behavior of an older adolescent and an adult are radically different. Only a limited part of adolescents can enter into adult economic relations and effectively study in economic universities in accordance with their individual and typological personality characteristics. However, the relationship between the individual characteristics of the individual and the ability of rational choice in young people is not fully revealed in the scientific literature.

\section{Methods}

\subsection{Theoretical and methodological framework of research}

An in-depth analysis of the correlation between the individual characteristics of students' personality and irrational behavior is provided in this paper. It analyzes correlation when students adopt financial strategies, solve issues in the field of money and finance. The authors developed a new diagnostic technique - a game for students simulating the reality of economic choice and behavior - based on the theory of perspectives of Tversky and Kaneman (1979). Most researchers argue that by the age of 15-16, high school students form an economic consciousness and behavior that are similar in structure and content to adults. Consequently, it is possible to speak about the formation of the cognitive level of development of the economic consciousness of adolescents close to an adult, but the other aspects, presumably, remain still insufficiently developed and differentiated. Comparing the psychological and behavioral characteristics of young people, the most significant differences in economic consciousness can be singled out in the research.

The empirical study entailed participation of 230 subjects aged mainly 17-18 years old (149 females and 81 males), first-year students of Plekhanov Russian University of Economics (Moscow) (Table 1). All students with secondary education follow the area of studies "Economics", program "Finance and Credit" and are citizens of Russia. It should be noted that gender differences were not included in the objective of the study; therefore, the group was considered entirely.

Table 1. Gender and age characteristics of a sampling (people)

\begin{tabular}{|l|l|l|l|l|}
\hline & 17 years & 18 years & 19 years & 20 years \\
\hline Females & 64 & 81 & 4 & \\
\hline Males & 31 & 41 & 4 & 5 \\
\hline
\end{tabular}

The research aims at studying the relationship between the psychological and rational behavioral characteristics of young people aged 17-18 with approximately the same 
level of (secondary) education who passed the entrance selection for admission to Plekhanov Russian University of Economics. The research was conducted by the method of statistical group comparison and analysis. A set of methods was used in the research:

1. Questionnaires and standardized interviews of the study of the economic and psychological characteristics of a person (Zhuravlev \& Kupreychenko, 2003).

2. Test of the meaningful life orientations of life-purpose orientations (LPO) (Leontyev, 2000).

3. Eysenck Personality Questionnaire Eysenck's Personality Inventory (EPI) neuroticism test (Eysenck, 1963).

4. Test of personality's self-assessment (Dembo, 1962; Rubinstein, 1970).

\subsection{Materials and methods}

To study the most important psychological characteristics of an individual affecting the irrationality of behavior, we conducted an analysis of the following emotional and personal qualities of young people: emotional and personal instability, selfassessment level, character type, and life-sense personal orientations. The study also included investigation of economic and psychological characteristics of an individual with the assessment of the personality's orientation to economic competition. To solve the task of identifying the formation of commitment to economic competition, questionnaires, a standardized interview and a test according to the method of Leontiev were used. The study of life-purpose orientations (LPO) (Leontiev, 2000) lies in tested subject's assessment of personal attitude to life on a five-point (factors) scale:

1. "goals in life", i.e., life goals, vocations, intentions in life;

2. "interest and emotional richness of life";

3. "satisfaction with self-realization" (expresses a feeling of success in self-fulfillment in life and daily activities);

4. "I am a master of life" (expresses a person's sense of the ability to influence the course of his/her life);

5. "manageability of life" (expresses confidence in the fundamental possibility of making life choices independently).

In Leontiev's opinion, diagnostics of life-purpose orientations makes it possible to identify fruitless dreamers among young people, their attitude towards themselves, their life, the presence or absence of future goals in their life, a sense of meaningfulness and interest in life, emotional intensity of life, the effectiveness of life or satisfaction with self-realization. High scores on the "Living Process" scale and low scores on the rest factors will characterize a young man living for today and not able to rationally assess the future. Too high and too low scores on the "Focus of Control-Life" scale indicate an excessive underestimation of risk and an excessive overestimation of the risk of young people, respectively. The author of this 
methodology assumes that the above contradictions in the elections reflect some lack of formation of attitudes on a few issues on economic competition and actions in terms of rationality of thinking.

The diagnostics of behavior rationality of life situations require rational economic choice. Young people were conducted by means of a game imitating real technique using the research materials (task ideas) of Kaneman and Tversky (1986), which were transferred to the economic field. The purpose of the game technique is to identify trends in the rational or irrational economic behavior of a first-year student.

\subsection{Characteristics of the research procedure}

The initial phase of the study concerned the identification of a predisposition to rational or irrational behavior when making economic decisions. According to our author's methodology, we evaluate the level of rationality of behavior based on an economic game that simulates decision-making under conditions of financial choice.

According to the results of the game, 150 students from 230 tested subjects receiving a positive financial result were identified. Carrying out several rational mental actions and steps in the field of making financial decisions allowed them to gain income (not a loss). Besides, the results of the game revealed 80 students out of 230 tested subjects who received a negative financial result, which may indicate wrong, irrational actions and steps taken in the game. Thus, we conditionally consider that 150 students belong to the group of rational behavior and 80 to irrational behavior.

It should be noted that the consecutive fulfillment of assignments from 1 to 4 , as well as assignments from 7 to 9 allows the student developing a strategy by trial and error (learning) that gives the greatest financial benefit, even if the one was initially inclined to act irrationally. In this way, one can trace the degree of rationality of an individual, depending on the step at which his rationality prevails over emotions and patterns of behavior and impulsive decisions. It should be noted that at the last, $10^{\text {th }}$ step, a student who previously acted rationally, under the excitement of the last opportunity, can receive a large positive financial result (to finally become a winner), take an inadequate risk disproportionate to his previous positive reinforcement actions.

Table 2. The results of the students' overcoming 10 stages in terms of the task of the author's methodology for assessing rational / irrational behavior, number of people

\begin{tabular}{|l|l|l|l|l|l|l|l|l|l|l|}
\hline № of the task & 1 & 2 & 3 & 4 & 5 & 6 & 7 & 8 & 9 & 10 \\
\hline Irrat. (people) & 156 & 131 & 117 & 76 & 93 & 142 & 111 & 70 & 7 & 42 \\
\hline Rat. (people) & 74 & 99 & 113 & 154 & 137 & 88 & 118 & 160 & 223 & 188 \\
\hline prevalence & irrat. & irrat. & irrat. & rat. & rat. & irrat. & rat. & rat. & rat. & rat. \\
\hline
\end{tabular}

As follows from Table 2, according to the results of the $1^{\text {st }}$ assignment, most students (156 people) demonstrated irrational behavior, and 74 people showed rational 
behavior. According to the results of the $2^{\text {nd }}$ assignment, most students (131 people) demonstrated irrational behavior, and 99 people showed rational behavior, the tendency continuing in the rest of the assignments. In Table 2, the cells with sign stages № 4, 9, and 10 marked with color are the so-called threshold of rationality, with the passage of which even a student prone to irrational behavior should already develop skills of rational thinking.

The next stage of the study was to assign each student a corresponding style of economic behavior. Economic behavior graded in 8 styles of behavior according to the financial results of the passage of each stage of the task. It also identified 7 students of atypical behavior that cannot be attributed to any of the above listed groups of behavior (Table 3).

Table 3. Students' behavior types according to the results of the assignments of the author's methodology for assessing rational / irrational behavior, number of people

\begin{tabular}{|l|l|l|l|l|l|l|l|l|}
\hline 1 & 2 & 3 & 4 & 5 & 6 & 7 & 8 & 9 \\
\hline $\begin{array}{c}\text { highly } \\
\text { irrat. }\end{array}$ & $\begin{array}{c}\text { pronounced } \\
\text { irrat. }\end{array}$ & $\begin{array}{c}\text { moderately } \\
\text { pronounced } \\
\text { irrat. }\end{array}$ & $\begin{array}{c}\text { moderate } \\
\text { irrational }\end{array}$ & $\begin{array}{c}\text { moderate } \\
\text { rat. }\end{array}$ & $\begin{array}{c}\text { moderately } \\
\text { pronounced } \\
\text { rat. }\end{array}$ & $\begin{array}{c}\text { pronounced } \\
\text { irrat. }\end{array}$ & $\begin{array}{c}\text { highly } \\
\text { rat. }\end{array}$ & $\begin{array}{c}\text { atypica } \\
1\end{array}$ \\
\hline $\begin{array}{c}6 \\
\text { people }\end{array}$ & 14 people & 34 people & 25 people & 31 people & 49 people & 34 people & 30 people & 7 people \\
\hline
\end{tabular}

The further stage of the research concerned the identification of the degree of selfassessment, emotional and personal stability, extraversion / introversion, and lifepurpose orientation of first-year students from each group of rational behavior. Answers to blocks of questions about lifestyle, self-assessment, life-purpose orientations, as well as about the degree of satisfaction of economic needs and economic claims, relationship to money, business activity and economic risk can create an image of student's economic and psychological behavior.

\section{Comparison of Styles of Behavior with Parameters of Life-purpose Orientations}

Based on the results of a study about the characteristics of a person's behavior and the manifestation of its psycho-emotional characteristics, the following features can be distinguished by groups of students, depending on their tendency towards irrational behavior.

The assessment of the life-purpose orientation "Goals in Life" by the selected styles using univariable analysis of variance showed no significant differences $(\mathrm{F}(8.199)=$ $1.300, \mathrm{p}<0.001)$. The correlation of the life-purpose orientation of "Goals in Life" with behavioral styles (Table 5) also turned out to be insignificant $(r=-0.099, \mathrm{p}>$ $0.05)$. 
The assessment of life-purpose orientation "Living Process" by the selected styles using univariable analysis of variance did not show significant differences ( $F(8.199)$ $=1.774, \mathrm{p}<0.001)$. The correlation of the life-purpose orientation "Living Process" with the behavioral styles (Table 5) also turned out to be insignificant $(r=-0.105, p>$ $0.05)$.

The assessment of the life-purpose orientation "Result of Life" by the selected styles using univariable analysis of variance did not show significant differences ( $F(8.199)$ $=0.758, \mathrm{p}<0.001)$. The correlation of the meaningful life orientation "Result of Life" with the styles of behavior (Table 5) also turned out to be insignificant $(r=-0.057, p>$ $0.05)$.

The assessment of the life-purpose orientation "Locus of Control - Me" by the selected styles using univariable analysis of variance showed significant differences $(\mathrm{F}(8.199)=2.234, \mathrm{p}<0.001)$. At the same time, the most pronounced differences were observed in the group with an extremely irrational style of behavior. However, the correlation of the level of the life-purpose orientation "Locus of Control - Me" with behavior styles (Table 5) was not significant $(\mathrm{r}=0.048, \mathrm{p}>0.05)$.

The assessment of the life-purpose orientation "Locus of Control - Life" by the selected styles using univariable analysis of variance showed significant differences $(\mathrm{F}(8.199)=2.755, \mathrm{p}<0.001)$. At the same time, the most pronounced differences were observed in the group with an extremely irrational style of behavior. The correlation of the level of the life-purpose orientation "Locus of Control - Life" with behavioral styles (Table 5) also turned out to be significant $(\mathrm{r}=-0.138, \mathrm{p}<0.05)$.

Table 4 presents the results of a statistical comparison of the average psychological methods for each style. It was revealed that all styles of rationality of behavior significantly differ according to the scale of life-purpose orientations "Locus of Control - Me" and "Locus of Control - Life".

Table 4. Univariable analysis of behavioral styles comparison with psychological parameters

\begin{tabular}{|l|l|}
\hline psychological parameter & significance of differences \\
\hline LPO Goals in life & 0.245 \\
\hline LPO Living process & 0.084 \\
\hline LPO Result of life & 0.640 \\
\hline LPO "Locus of control - Me" & 0.026 \\
\hline LPO "Locus of control - Life" & 0.007 \\
\hline
\end{tabular}

After conducting a correlation analysis between all styles of behavior rationality (except atypical) based on the assumption that they are ordered on a rationalityirrationality scale a significant relationship was found with the life-purpose orientation "Locus of control - Life" (Table 5). 
Table 5. Correlation analysis of the comparison of behavioral styles with psychological parameters

\begin{tabular}{|l|l|l|}
\hline Psychological parameter & Pearson correlation & $\begin{array}{l}\text { significance of differences (of 2 } \\
\text { sides) }\end{array}$ \\
\hline LPO Goals in life & -0.099 & 0.160 \\
\hline LPO Living process & -0.105 & 0.136 \\
\hline LPO Result of life & -0.057 & 0.421 \\
\hline LPO "Locus of control - Me" & 0.048 & 0.500 \\
\hline LPO "Locus of control - Life" & $-0.138^{*}$ & 0.049 \\
\hline
\end{tabular}

Note: * Correlation is significant at 0.05 level.

\section{Findings}

Evaluating the entire representative sample for comparison of the economic and psychological characteristics of the personality of Zhuravlev-Kupreychenko, it was found that most respondents preferred the same characteristics. However, contradictions were identified in the following categories:

- opportunities for increasing personal incomes and family incomes are evaluated differently by the same respondents;

- most of the subjects have low business activity, a desire for comfortable (not hard) work, and at the same time prefer high income, ownership of property and management of an enterprise;

- most of respondents see themselves as business owners, and at the same time only $30 \%$ of them like to work in a competitive environment and they prefer to work in such conditions.

The contradictions in the elections reflect the lack of formation of students' commitment to several issues related to economic competition and actions in the context of rational thinking. According to the results of the analysis of the relationship of behavioral styles with the economic and psychological characteristics of Zhuravlev-Kupreychenko, it is found out that the relationship of behavioral styles with economic and psychological characteristics has not been identified, the dependence of the frequency of choice of factors "Stressful/comfortable work", "Contractor/Manager", "Economic risk/Stability", "Employee/Owner", "High/Low Income", the tendency to compete against the presence of irrational behavior is not statistically significant.

The analyzed economic and psychological characteristics make it impossible to identify the predisposition factor for irrational choice, since the frequency of distribution is at the level of a statistical trend.

It was revealed that the share of emotionally unstable young people prevails in the group "Highly irrational behavior" (average score of 20). Whereas, as the degree of rationality increases, the degree of emotional instability decreases to the average score 
of 9 in the group of "Highly rational behavior". Thus, the share of emotionally stable young people grows as the style of behavior changes towards a more "rational" one.

The high level of neuroticism in a group of students prone to irrational behavior ("Highly irrational behavior") indicates their high emotional instability, what can characterize the young man's inclination to make rash and inconsiderate decisions due to the lack of dispassionate, sound thinking. It can be assumed that young people with insufficient emotional and personal stability may overestimate the benefits of their decisions and underestimate the risks.

Analyzing the average indicators by temperament by groups, it can be noted that students of all groups belong to ambiversion (communication when an individual need it). But students from irrational groups are prone to extroversion, they are sociable, open to the outside world. While students of rational behavior groups are prone to introversion, isolation. Levels of differences in groups depending on temperament are not significant.

It was also revealed that an overstated self-assessment of young people is typical for a group "Highly irrational behavior" (average score 63) and high self-assessment for the group "Pronounced irrational behavior" (average score 50.5), while the average score of self-esteem level for all students is 45 , which corresponds to the upper limit of the average level of self-esteem. The study allows us to formulate a number of conclusions:

1. Conducting diagnostic methods resulted in retrieving data that reveal the following: such individual psychological characteristics of an adolescent as emotional stability, self-assessment, and life orientations can influence his/her rational choice.

2. The main hypothesis of the study - presence of the connection between personality traits and an irrational choice when making economic decisions for students of economic universities - was confirmed. The private hypothesis - individual and typological personality traits, such as the meaningful life-purpose orientations "Locus of Control - Me" and "Locus of Control - Life" may be the factors of irrational behavior and choice among students - was also confirmed.

3. According to the results of an empirical research based on a reality-simulating game, various styles of students' irrational behavior were identified. In the study of irrational behavior of a group of students who are inherent in the style of "Highly irrational behavior" (about 3\% of the students in the experimental group), a high degree of emotional instability and inflated self-assessment were found.

\section{Discussion}

Taking the approach of Tversky and Kaneman (1979) described in the theory of perspectives as a basis to explain the irrationality of human economic choice in the framework of "cognitive illusions", a game was developed for students that simulates the reality of an economic choice and behavior. The influence of individual 
psychological personality traits, character on the formation of deviations from rational choice in adolescence is investigated.

Application of diagnostic and gaming techniques resulted to obtaining data confirming that emotional instability, high self-assessment, inflated indicators for lifepurpose orientations "Locus of control - Me" and "Locus of controls - life" are risk factors for studying in economic universities and poor learning material for making rational financial decisions. Besides, as a result of using diagnostic methods, obtained data revealed that such individual psychological characteristics of an adolescent as emotional stability, self-assessment, life-purpose orientations can influence adolescent's rational choice. This phenomenon requires further in-depth research.

To gain the reliability of research results, it is necessary for the future to take into account the fact that the beginning of studies at the university is a highly stressful life period for young people: it presents a critical life event (change in the stage of the life cycle), as well as in a number of institutions of higher learning overload.

Therefore, these factors could affect the objectivity of the study of behavior irrationality. Also, when conducting future research in this area, possible coping strategies and psychological defenses should be considered. The psychological defenses can be formed in the course of studies at the beginning of university life under the influence of this stress.

However, understanding how the individual characteristics of a young man are manifested in the educational process in economic disciplines, parents and specialists can adjust the learning environment to the one so that the young man can effectively study economic disciplines.

It should be noted that the number of studies made is not enough for high reliability of the result or an objective quantitative analysis. It is necessary to test this hypothesis using a sample of 500-600 students of this age from other economic universities. However, the first results obtained show the prospects of further research.

\section{References:}

Becker, G. 1976. The Economic Approach to Human Behavior. Chicago Press, 320.

Bell, D., Raïffa, H., Tversky, A. 1988. Decision making: Descriptive, normative, and prescriptive interactions. Cambridge, Cambridge University Press, 623.

Camerer, C. 2003. Behavioral game theory: experiments in strategic interaction. New York Princeton, New Jersey, Russell Sage Foundation Princeton University Press.

Dembo, T.V. 1962. Adaptation to injury - the problem of socio-psychological rehabilitation.

Eysenck, H.J., Eysenck, B.G. 1964. Manual of the Eysenck Personality Inventory. London, Hodder \& Stoughton.

Knight, F. 1921. Risk, Uncertainty and Profit.

Leontiev, D.A. 2000. The test is a meaningful life orientation (LSS). 2nd edition, Moscow, 18. 
Rubinshtein, S.Y. 1970. Experimental methods of patho-psychology and experience of their use in the clinic. Moscow.

Tversky, A., Kahneman, D. 1979. Prospect theory: An analysis of decision under risk. Econometrica, 2(47), 263-291.

Tversky, A., Kahneman, D. 1986. Rational choice and the framing of decisions. Journal of Business, 4(59), S251-S278.

Tversky, A., Kahneman, D. 1991. Loss aversion in riskless choice: A reference-dependent model. Quarterly Journal of Economics, 4(106), 1039-1061.

Zhuravlev, A.L., Kypreychenko, A.B. 2003. Moral and psychological regulation of economic activity. Moscow, 436. 